\title{
Development of a psychiatric liaison service
}

\author{
D Black, A McFadyen, G Broster
}

Physicians have been aware of the links between psychological processes and physical illness for centuries, and over 30 years ago Alexander described these links in a number of classical psychosomatic diseases. ${ }^{1}$ More recently, systemic thinking has aided our understanding of the processes, and contributed to our management of both organically and non-organically induced physical complaints. The interactive and circular nature of the relationship between psyche and soma have been illustrated by Minuchin et al (figure). ${ }^{2}$

Psychological sequels of both childhood illness and admission to hospital have also been documented. ${ }^{34}$ The value of a systemic approach to paediatrics - that is, seeing the child in the context of his family and social surroundings - has been highlighted by Bingley et al. ${ }^{5}$

'Liaison child psychiatry' refers to the partnership of child psychiatry, paediatrics, and other specialities concerned with children to provide integrated medical and psychological care for children. The development of liaison services has been described by a number of authors, ${ }^{6-8}$ and different models of functioning have been proposed. ${ }^{9-12}$ Obstacles to liaison, ${ }^{13-15}$ and ways of overcoming them, ${ }^{16} 17$ have also been discussed. Graham has outlined principles of referral appropriate to a child psychiatry consultation service, but has pointed out that these are less necessary when there is regular contact between specialists. ${ }^{18}$

\section{Description}

The Royal Free Hospital in north London is a teaching and district general hospital serving a population of approximately 100000 . It is the supraregional centre for the management of end stage renal failure and for bone marrow transplantation in children. The first child psychiatrist was appointed in 1971, but after a new consultant appointment had been made in 1984 a decision was made to concentrate the small resources of the department on paediatric and child psychiatry \footnotetext{
Royal Free Hospital London London

The Tavistock Clinic, 120 Belsize Lane, London NW3 5BA A McFadyen

G Broster

Correspondence to Dr McFadyen.

Accepted 25 April 1990
}

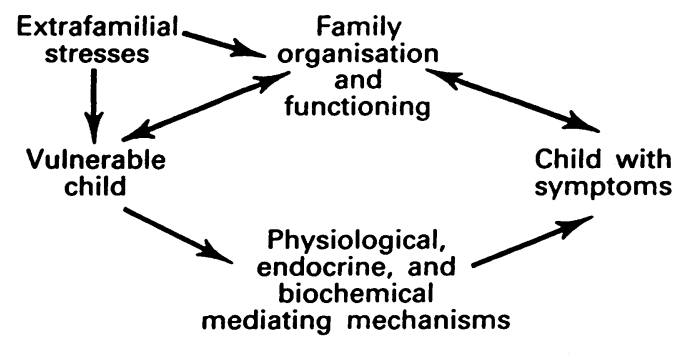

'Open systems' model of psychosomatic disease. ${ }^{2}$ liaison. An awareness of a subsequent change in the pattern of referrals to the child psychiatry department following this decision led to an attempt to assess this in detail. An analysis of the work of the liaison service from mid-1984 to mid1987 was carried out using a model similar to that used by Brown and Cooper in a study of an adult psychiatric liaison service. ${ }^{19}$ This paper summarises some of the main findings of the analysis of referrals and considers the possible reasons for the changes. The study is described in detail elsewhere. ${ }^{20}$

\section{Results}

Most liaison referrals $(n=120)$ were of inpatients on the paediatric ward $(55 \%) ; 12.5 \%$ were inpatients on other wards. Most were made by paediatricians $(66 \%)$; the others came from a wide range of hospital specialists, usually haematologists, but also neurologists, psychiatrists, surgeons, and oncologists. The bulk of referrals were either requests for help in the management of physical illness or requests for help with diagnosis in cases where no organic cause could be found for a physical complaint. The main finding of the study concerns the pattern of referrals over the three year period. Liaison referrals increased significantly in contrast to total referrals and also in contrast to the numbers of cases of self poisoning or self injury that were referred (table).

DEVELOPMENT OF THE SERVICE 1984-7

In addition to the already established referral system, a number of services and structures were developed by the child psychiatrist and the paediatricians to try and improve the service to children and their families, and the liaison between specialities and disciplines.

\section{Psychosocial ward rounds}

Until 1984 the weekly psychosocial round was not attended by a consultant paediatrician, and there was no regular time for the consultant paediatrician and child psychiatrist to meet. Since 1984 a weekly meeting of consultant child psychiatrist

Referrals to department of child psychiatry during period of study

\begin{tabular}{lcccl}
\hline & $1984-5$ & $1985-6$ & $1986-7$ & $p$ Value* \\
\hline $\begin{array}{l}\text { Total referrals } \\
\text { Liaison referrals }\end{array}$ & 116 & 104 & 124 & NS \\
$\begin{array}{l}\text { Referrals for self } \\
\text { poisoning or injury }\end{array}$ & 7 & 14 & 13 & NS \\
\hline
\end{tabular}

${ }^{*}$ Linear logistic analysis. $\mathrm{tz}=2 \cdot 59$. 
with each consultant paediatrician was arranged after the medical round. Members of both teams are present together with nursing staff, teacher, social worker, and liaison health visitor. All contribute to a discussion about the psychosocial aspects of each case in the ward under the care of that consultant paediatrician.

Regular liaison rounds with the haematology team have also been established. The most consistently useful function of these meetings has been the sharing of information, whereby each staff member has been able to make a unique contribution to a total picture of the child and his family. An increased knowledge of the illness and its prognosis has allowed all staff to work with each patient with greater patience and understanding.

For example, many staff felt that continued attempts to sustain the life of a 7 year old girl who had had an unsuccessful bone marrow transplant and was dying were placing an intolerable stress on the child, her family, and the nursing staff. The meetings provided an opportunity to express anger about this policy, to question its validity, and to seek to modify it. Meanwhile a child psychotherapist and a social worker worked directly with the child and her family, helping them to come to terms with what was happening.

\section{An emergency service}

Each day one member of the child psychiatry team makes sure that she has some free time to be available for emergencies.

For example, early in our association, a 13 year old boy was referred, who had become panic stricken, sleepless, and disturbed several weeks after receiving a renal transplant. He was seen immediately with his mother on the ward. He had dreamed that the donor had returned to haunt him and was afraid that he would ask for his kidney to be returned. Discussion uncovered a family belief in ghosts and in heaven. The psychiatrist was able to relabel the ghost as a friendly one who was checking that his kidney was being put to good use as it was no longer of use to him, just as the boy was pleased to know that his outgrown clothes were of use to other children.

By responding rapidly and effectively we have been able to reduce patient, family, and staff anxieties and establish ourselves as useful and reliable. Feedback about our work enables ward staff to anticipate similar problems and intervene earlier to prevent the consequences.

\section{Monthly meetings with ward staff}

Regular meetings act as a forum for thinking about how to improve the ward milieu in contrast to the consideration of the needs of each patient.

\section{Staff support}

A group of student nurses meet each week with the child psychotherapist to discuss their feelings about the nature of their work on the ward-for example, their own conflicting feelings about the rigorous treatment of children with leukaemia.

\section{Playleaders}

The child psychiatrist has been responsible for the appointment, guidance, and teaching of a full time hospital play specialist.
'Ward granny' scheme

The service of a volunteer to befriend a child and his family allows the parent(s) of inpatients to take breaks to rest or to care for other family members. 'Ward grannies', who originally 'parented' children 24 hours a day, as described by Robertson, are now used less frequently than when the scheme was first introduced in $1984 .^{21}$

\section{Teaching of medical students}

Until 1984 medical students received only four hours of teaching in child psychiatry, which has increased over the past three years to over 40 hours. Ten of these are in the paediatric block to integrate the physical and psychological aspects of illness by relating the teaching to cases and the student's personal experiences on the paediatric ward. Issues about 'death and dying,' for example, are discussed using role play as well as more conventional teaching methods. ${ }^{22}$

\section{Grand round}

Regular presentations at the hospital grand round were initiated by the consultant child psychiatrist. These make medical staff more aware of the services that the department can offer, and may also dispel fantasies that some may have about child psychiatrists.

For example: a 15 year old boy was referred by the oncologist, who had discovered that he was illiterate and was not attending school. At the age of 6 an operation to remove a medulloblastoma had been performed and an uncertain, but basically poor, prognosis had been given to his parents. His mother had subsequently felt unable to insist on his attending school against his will, reasoning that it was cruel to do so if he had only a short time to live. His father, who always brought him for his medical checks, was unaware of his nonattendance and the school, told of his prognosis by his mother, did not feel able to act. Liaison with the oncologist enabled the family to accept the lifting of the outdated poor prognosis. Family treatment facilitated improved communication within the family, and helped them negotiate the 5 year old sister's entry to school. We arranged for the boy to attend our hospital school after teaching him to recognise the tube station at which to alight. He learned to read and calculate in one year, left school, and is currently working as a hospital porter.

\section{Postgraduate education}

Child psychiatry academic meetings are open to paediatricians. In addition, fortnightly seminars led by members of the child psychiatry team are open to hospital staff and are regularly attended by teachers, nurses, social workers, and play specialists. Workshops about 'Working with families facing life threatening illness' and 'Working with children with physical illness' have been run for several years. Recently the child psychotherapist has considered the specific problems facing teachers in the hospital.

\section{Publications}

The child psychiatrist initiated and supervised the production of an information booklet about the child in our hospital (for parents) and contributed 
to one about the management of the care of dying patients (for staff). Further publications have dealt with the needs of specific groups-for example, children with blood disorders and end stage renal failure, as well as those of children on the general paediatric ward.

\section{Prevention}

Child psychiatrists now play a routine part in the assessment and management of all children admitted for bone marrow transplant or for the management of renal failure, and hopefully facilitates prevention or early detection of psychological problems.

\section{Research}

Joint research projects have been set up and have led to improved communication and mutual understanding.

\section{Discussion}

Naylor and Mattsson, in their account of the development of their own service, have emphasised the need to 'actively reach out' to paediatric colleagues, ${ }^{6}$ but like Josse and Challener, ${ }^{8}$ temper this with advice also to keep one's distance. The latter suggest that 'the skill comes with learning when to press on and when to hold back'.

Greene, in her consideration of the resistances to mutual collaboration, warns the child psychiatrist 'whose task is to convert disbelievers' that he may become a 'burned out missionary', 13 and indeed one of the obstacles to liaison may be the overzealous approach of colleagues who hold a specific and narrow point of view about their role. Paediatricians' beliefs about the characteristics of child psychiatrists will influence their use of-and participation in-a liaison service. Criticisms include comments about attitudes and poor communication. ${ }^{15}$ Paediatricians and child psychiatrists work in different ways, and misunderstandings may occur about the perceived urgency of referrals or speed of response. ${ }^{17}$ It is important that the child psychiatrist communicates clearly and effectively with all staff, and also that he is able to be available when necessary, rather than sticking to a rigid appointments system. There is little doubt that effective interventions by child psychiatrists do improve confidence, and this seems to be the case even when the intervention is relatively simple (as in the second example described). Following up an intervention with an explanation about underlying principles may result in the prevention of further psychological morbidity.

Greenberg and Rice (among others) believe that undergraduate and postgraduate medical and paramedical training can lead to increased sensitivity and awareness of emotional problems by the medical team. ${ }^{16}$ Staff support, particularly for those facing recurrent childhood deaths, is another forum for the development of insights, both into the family's ordeal and ways of working together. ${ }^{10}$ The psychosocial ward round is also recognised as a useful forum for the dissemination of ideas."

Each area of mutual collaboration provides an opportunity for the development of the relationship between professional groups and, as noted by one of the authors in another setting, may also lead to a better defined and more realistic expectation of the service. ${ }^{19}$

\section{Conclusion}

In this paper we have listed a number of institutional changes that reflect the development of the child psychiatry liaison service at the Royal Free Hospital. The services and structures introduced by the child psychiatrist provide opportunities for paediatric and psychiatric staff to work together for the benefit of their patients. Regular ward rounds and educational meetings, and the provision of staff support, have led to improved relationships between the specialities. We believe that the increase in the number of liaison referrals has been a direct result of these changes. It is important to note, however, that much of the liaison work of the child psychiatry team is done 'at a distance'-that is, with staff rather than directly with patients.

We consider that the development of this child psychiatry liaison service has been both appropriate and valuable, and hope that it will lead to a reduction in the well recognised and well described sequels to both illness and hospital admission in children.

We thank the staff at the Royal Free Hospital.

1 Alexander F. Psychosomatic medicine: its principles and applications. London: George Allen and Unwin, 1952.

2 Minuchin S, Rosman B, Baker L. Psychosomatic families: anorexia nervosa in context. Cambridge, Massachusetts: Harvard University Press, 1978.

3 Prugh DG, Staub EM, Sands HH, Kirschbaum RM Lenihan EA. A study of the emotional reactions of children and families to hospitalisation and illness. Am $\mathcal{F}$ Orthopsychiatry 1953;23:70-106.

4 Mrazek DA. Paediatric hospitalisation: understanding the stress from a developmental perspective. In: Christie MJ, Mellet PG, eds. The psychosomatic approach: contemporary practice of whole person care. London: John Wiley, 1986

Bingley L, Leonard J, Hensman S, Lask B, Wolff O. The comprehensive management of children on a paediatric ward-a family approach. Arch Dis Child 1980;55:555-61.

6 Naylor KA, Mattsson A. 'For the sake of the children': trials and tribulations of child psychiatry-liaison service. Psychiatry in Medicine 1973;4:389-402.

7 Ahsanuddin KM, Adams JE. Setting up a paediatric consultation-liaison service. Psychiatr Clin North Am 1982; 5:259-70.

8 Josse JD, Challener J. Liaison psychotherapy in a hospital paediatric diabetic clinic. Arch Dis Child 1987;62:518-22.

9 Mattsson A. Child psychiatric wards rounds on paediatrics. fournal of the American Academy of Child Psychiatry 1976; 15:357-65.

10 Whitt JK, Hunter RS, Dykstra W, Lauria MM, Stabler B, Taylor CA. Paediatric liaison psychiatry: a forum for separation and loss. Int $\mathcal{F}$ Psychiatry Med 1981-82;11:59-68.

11 Jellinek MS, Herzog DB, Selter LF. A psychiatric consultation service for hospitalised children. Psychosomatics 1981, 22:29-33.

12 Jones J. Liaison psychiatry in a paediatric oncology clinic. Bulletin of the Royal College of Psychiatrics 1988;12:213-5.

13 Greene CM. Mutual collaboration between child psychiatry and paediatrics: resistances and facilitation. Developmental and paediatrics: resistances and facilitation.

14 Fritz GK, Bergman AS. Consultation-liaison training for child psychiatrists: results of a survey. Gen Hosp Psychiatry 1984;6:25-9.

15 Fritz GK, Bergman AS. Child psychiatrists' characteristics, communication, and competence as described by paediatricians in a national survey. Int $\mathcal{f}$ Psychiatry Med 1986-7;16:91-100.

16 Greenberg LW, Rice HW. A paediatric-child-psychiatry liaison program in a community hospital. $\mathcal{F}$ Med Educ 1980 55:112-9.

17 Anders TF, Niehans M. Promoting the alliance between paediatrics and child psychiatry. Psychiatr Clin North Am 1982;5:241-58.

18 Graham P. Paediatric referral to a child psychiatrist. Arch Dis Child 1984;59:1103-5.

19 Brown A, Cooper AF. The impact of a liaison psychiatry service on patterns of referral in a general hospital. $B r f$ vice on patterns of refe

20 McFadyen A, Broster G, Black D. The impact of a child psychiatry liaison service on patterns of referral. $\mathrm{Br} \mathcal{J}$ Psychiatry (in press).

21 Robertson J. Young children in hospital. London: Tavistock, 1970.

22 Black D, Hardoff D, Nelki J. Educating medical students about death and dying. Arch Dis Child 1989;64:750-3. 